\title{
PIMENTEL, Luz Aurora. (2019). Constelaciones II. Cuadros color de tiempo: Ensayos sobre Marcel Proust. México: Bonilla Artigas Editores/ FFyL-UNAM.
}

Cuadros color de tiempo: Ensayos sobre Marcel Proust reúne las reflexiones enseñadas, escritas y reescritas por Luz Aurora Pimentel a lo largo de los cuarenta años que han transcurrido desde su primer deslumbramiento ante los siete libros del escritor francés quien, como ella misma dice, cambió su vida. Se trata del segundo volumen de una serie de cuatro que, bajo el título de Constelaciones, sigue a Ensayos de Teoría narrativa y Literatura comparada (2012).

El nombre de la colección se inspira en los estudios que Gérard Genette escribió entre 1959 y 1972 llamados Figuras I, II y III. Estas compilaciones parecen no tener una relación de continuidad, aunque estén ligadas por un fondo teórico y se trate, como el mismo Genette pretendía, de una manera de acceder a la esen-

\author{
IRENE ARTIGAS ALBARELLI \\ Facultad de Filosofía y Letras \\ Universidad Nacional Autónoma de México
}

cia de las cosas, sobrepasando las apariencias a través de la expresión de una visión profunda (Figures I). Como Genette, Pimentel reúne en este libro ensayos críticos que, aunque distribuidos en tres secciones bien delimitadas y organizadas, pueden también leerse siguiendo el orden que quien lee determine y que dará forma a distintas constelaciones posibles. La autora considera, como expresa en "Palabras preliminares", que gran parte del valor de este volumen es la selección de los fragmentos de la obra de Proust, que orientaron cada uno de los capítulos en torno a un tema propuesto y que, al iluminarse entre sí, proponen una perspectiva diferente de la que una secuencia única produciría. Se trata de "Pasajes [...] reunidos como un ramillete - florilegio se decía antaño, en 
otro tiempo, en otro mundo-, un ramillete de textos ofrecido al lector para una (re)lectura desde la perspectiva especial que le otorga el conjunto" (16-17). Aprovecharé esta analogía con un ramillete para ejemplificar una de estas constelaciones posibles producida por la red que Cuadros color del tiempo presenta en torno a las flores en la obra de Proust.

En el capítulo titulado "Las magdalenas y pepsinas de la tía Léonie”, Pimentel nota cómo la descripción que Proust hace de los tallos de la flor del tilo (recordemos que la famosa magdalena que siempre identificamos al pensar en estos libros se remoja en té de tila) se vuelve también una descripción simbólica de la tía Léonie, "en el crepúsculo de su floración” (98), además de una especie de caja china de la poética proustiana. Comentando el siguiente fragmento de Proust:

Los tallos de la flor del tilo, al secarse, se curvaban, formando un caprichoso enrejado, entre cuyos nudos se abrían las pálidas flores, como si un pintor las hubiera colocado y dispuesto del modo más decorativo. Las hojas, al cambiar de aspecto, al perderse totalmente, se asemejaban a cosas absurdas, al ala transparente de una mosca, al revés de una etiqueta o a un pétalo de rosa, pero que hubieran sido todas ellas apiladas, trituradas y entretejidas como en la confección de un nido. Mil pequeños pormenores inútiles [...] modificados precisamente porque eran de verdad y no copias y habian envejecido. (98)

Pimentel nos explica, nos convence, de que algo de todo esto está también en la tía Léonie y en toda la obra, de que este carácter heterogéneo, fragmentado y disparatado es la pedacería que, parchada, se vuelve metáfora de los siete libros: "Por otra parte, la descripción de los tilos insiste en la visión estereoscópica tan peculiar a Proust: esa capacidad de ver el pasado y sus metamorfosis en el presente; esa lectura de la vida en palimpsesto que le confiere densidad y realidad; no un 'compuesto facticio' sino la alegría del reconocimiento, la alegría de lo real recobrado en y por el tiempo" (99).

Si, como apunta Pimentel en "Por el camino de Santiago: éxtasis, revelación y arte", la experiencia de la magdalena en 
el té "se convierte en un paradigma, en un verdadero ‘algoritmo’ del éxtasis y la revelación” (53), las flores del tilo para el té son en sí mismas ya una de dichas experiencias que se contienen a sí mismas, "semejantes entre sí y diferentes de todo orden de vivencias" (53). A esta "perpetua aliteración” (129) paradigmática se referirá Pimentel más adelante al comentar el fragmento de Proust en el que Marcel se entretiene observando a unos muchachos que en el río llenaban sus garrafas con el agua de la corriente y describirlo como "el equivalente de esta experiencia de unidad" (129). Tanto el "agua endurecida" como el "cristal líquido" reverberan en la "allitération perpétuelle" subrayada por Pimentel del cristal que pierde su consistencia y del agua que deja de fluir, y en la experiencia que se extiende hasta quien lee estas páginas multiplicadas por la identificación de las redes metafóricas que seguramente, sin ellas, no habríamos notado. El té de las flores del tilo contiene tanto el presente como el pasado y el futuro que los recuperará en la memoria de quien saborea la magdalena remojada: "la fascinación por la experiencia de una entidad 'continente' a su vez 'contenida"' (129).
En "Por el camino de Swann, por el camino de Guermantes: una topografía espiritual", Pimentel analiza otra red descriptiva conformada por flores: los setos de espinos blancos y los "susurros de su aroma” (133) en los paseos de Marcel en Tansonville, cuya contemplación lo exaltan justo antes de que aparezca por primera vez Gilberte Swann. Estos setos establecen una secuencia con los que se describieron páginas antes de manera exactamente invertida: la primera vez flores campestres, como de un seto salvaje en un altar; la segunda, la de los espinos blancos en el paseo, en términos de arquitectura eclesiástica. La primera vez transformada en Mlle. Vinteuil, la segunda en Gilberte:

Mímesis de la flor: equivalente espiritual profundo de la impresión recibida. Aquí de manera insospechadamente aristotélica, imitar (“mimer") no es copiar; es transponer, encontrar un equivalente, crear. Según Proust al contemplar un objeto, éste queda incorporado a nuestra subjetividad, de tal manera que su realidad no reside únicamente en el ser exterior del objeto, sino también en 
el objeto en tanto percibido, y por ende significado. La única forma de incorporar al objeto de manera significante es mediante un arduo trabajo de transposición, de desciframiento; una búsqueda del "equivalente espiritual" que le dé sentido: una mímesis interior. Es por ello que, más allá y en contra de una poética realista que propone "copias fieles" de la realidad observada, para Proust la imitación profunda de una flor no es otra flor idéntica o semejante... jes una muchacha! (134-135)

Estas posiciones estructurales idénticas obligan a Pimentel a notarlas y buscarlas más adelante como metáfora sostenida en la base de $A$ la sombra de las muchachas en flor. "Todas aquellas mujeres que habrán de ser transformadas en flores, desde Mme Swann y Albertine pasando por André, Giselle y hasta Rosamonde, serán siempre objeto de sospecha, seres de fuga que siempre podrían escapar a la terra incognita del lesbianismo" (137). La sorprendente lectura basada en la narración metafórica que la autora había desarrollado ya en libros anteriores "florece" en aproximaciones tan originales y creativas como ésta.

El último ejemplo al que me referiré de las redes de significación desplegadas en torno a las flores está en el fascinante "La moda en Proust: una pasarela en el tiempo", en donde se hacen desfilar de ida y vuelta las descripciones que aparecen en En busca del tiempo perdido de la ropa de Mme Swann, la Duquesa de Guermantes y Albertine. Se trata de una "lectura evocadora" (188) del vestido como "tiempo materializado", como "el aparato fino y espiritual de una civilización” (187), que puede notarse en pasajes como el siguiente:

De repente se mostraba en la arena de la avenida Mme Swann, tardía, despaciosa y lozana, como flor hermosísima que no se abre hasta la hora del mediodía, desplegando una toilette siempre diferente, y que en mi recuerdo es sobre todo color malva; en seguida izaba y abría, sustentada en un largo pedúnculo, y en el momento de su más completa irradiación, el pabellón de seda de una amplia sombrilla del mismo tono que aquellos 
pétalos que se deshojaban de su falda. (220)

Al "suspenso sintáctico" ya identificado en otros fragmentos y anunciado en el "de repente", Pimentel añade que Mme Swann llega no sólo ya como una mujer, sino como flor, "los volantes de su vestido son los pétalos de esta flor que sólo se abre al mediodía, el astil, o poste, de su sombrilla, no es otra cosa que el pedúnculo que sostiene a esta flor" (221). El comentario en la nota inmediata sobre la imposibilidad de entender todo esto en la traducción al español da cuenta de parte de todo el trabajo, el tiempo y la complejidad necesarias para escribir este libro: "Nuevamente, la traducción es engañosa: traduce "l'effeuillaison des pétales de sa robe" como "pétalos que se deshojaban de su falda”, como si los pétalos fueran exteriores a la falda, venidos de alguna flor y no, como lo propone la metáfora, constitutivos de la falda misma, de la mujer en tanto que flor" (221). Pimentel lee a Proust en francés, en español según traducciones de varias voces, cambiándolas cuando el sentido cambia demasiado o comentándolas cuando las diferencias de los idiomas lo ameritan, como en este caso.

Debo advertir que a estos ejemplos que resumí de las redes que este libro presenta en torno a las flores se pueden añadir otras, por ejemplo, la tratada en el capítulo llamado "La sombra de las muchachas en flor". Leer ese último ensayo del libro convence de la "aparente astucia” de las flores en Proust. Y en Pimentel. Recorridos semejantes podrían hacerse en Cuadros color del tiempo con respecto al mosaico, a los edificios, a los caminos, a los colores, a la escritura, al tiempo... La expresión privilegiada de Pimentel nos permite, a partir de textos y secciones fijas, crear otros ramilletes en un libro que, como la obra que analiza, subraya la imposibilidad de realmente terminar alguna vez de escribir y de leer. No me queda más que esperar que Pimentel no haya realmente decidido terminar de leer a Proust. 